\section{A lógica de}

\section{consumo e produção} do espetáculo no

\section{Estado}

\section{burocrata}

\section{RESUMO}

A partir da afirmação de que as populações têm demonstrado cada vez menor interesse pela polítuca, a autora faz um estudo relacionando a sociedade de consumo e as estratégias de marketing, seguindo o pensamento de Habermas, que detecta esta alteração em sua obra Mudança Estrutural da Esfera Pública, e o de Baudrillard, em Tela Total, que também argumenta sobre a ausência de dialética entre o público e a classe política.

\section{ABSTRACT}

This article studies the interelationship between consumer society and marketing strategies based on writings of both Habermas and Baudrillard.

\section{PALAVRAS-CHAVE /KEY-WORDS}

- Esfera pública (Public Sphere)

- Sociedade de consumo (Consummer Society)

- Marketing

\section{Maria Luiza Sacknies da Silva Mestre/PUCRS}

MUITOS AUTORES VÊM afirmando que as populações têm demonstrado cada vez menor interesse pela política, que vem, com o passar dos anos, se burocratizando cada vez mais. Habermas é um dos pensadores que detecta esta alteração em sua obra Mudança estrutural da esfera pública. Baudrillard, em Tela total, também ressente-se da ausência de dialética entre o público e a classe política.

Para melhor compreender o pensamento de Habermas, é necessário retornar à primeira fase do capitalismo e rever a evolução da imprensa até a atualidade, já que, de acordo com o autor, é ela a instituição por excelência da esfera pública. Dessa forma, através do desenvolvimento da imprensa, será possível, também, observar o desenvolvimento da esfera pública e sua relação com o público.

Nesse período, o editor era apenas um mero veiculador de notícias, cujo interesse por sua empresa se mantinha dentro de aspectos exclusivamente comerciais. Posterior a isso, surgiu o jornal de opinião pública. Veículos que se propunham ser meios de luta política, que eram conduzidos por escritores e intelectuais que viam ali um espaço para veicular suas idéias cheias de "intencionalidade didática". $\mathrm{Na}$ Inglaterra, esse mesmo movimento em que as pessoas privadas se manifestavam enquanto público foi mantido pela aristocracia conservadora.

Ainda assim, alguns veículos mantiveram, até o século XIX, a mesma estrutura tradicional, em que o redator era também dono da editora e responsável direto por todo o processo de confecção 
do jornal. Isso acontecia especialmente nos periódicos que se mantiveram ao largo da luta politico-literária que tomou conta das redações nesse período.

De qualquer forma, havia, então, um movimento na imprensa, que se desenvolvia a "partir da politização do público e cuja discussão ela apenas prolongava". Ainda assim, ela não podia ser considerada um instrumento da cultura consumista, o que só foi acontecer na primeira metade do século XIX, quando os veículos abandonaram suas posições polêmicas e passaram a assumir as chances de lucro de uma empresa comercial.

Assim, a imprensa começou a reservar espaço para anunciantes e ser "pórtico de entrada de privilegiados interesses privados na esfera pública", que aqui não deve ser compreendida como poder público, mas, ao contrário, como um espaço público. A edição e avaliação das notícias passaram a receber maior atenção que os artigos de artistas ou jornalistas famosos. Nesse período, a imprensa deixa de ser um órgão que reforça as opiniões das pessoas privadas transformadas em um público, para iniciar, de acordo com o autor, um processo de formação de opinião pública.

Quanto à publicidade, é somente na segunda metade do século XIX, com o desenvolvimento do capitalismo industrial, que ela começa a alcançar um volume considerável. Até então, esta estratégia não possuía credibilidade e tampouco era bemvista pelos comerciantes tradicionais, que preferiam a "propaganda" cara a cara.

É justamente na análise do desenvolvimento da publicidade que podemos perceber de forma mais clara as sucessivas alterações na relação entre a esfera pública e o público: a publicidade e a propaganda assumem a responsabilidade de não somente representarem um objeto, mas de emprestarem a ele a "autoridade de um objeto de interesse público". Elas mobilizam para o objeto "uma espécie de respeito que só se teria para com autoridades públicas".

Assim, enquanto a publicidade de empresas privadas direciona o público para uma "atividade consciente", onde ele é capaz de se manifestar e tornar-se um cidadão, a atividade pública, na forma do Estado, volta-se aos cidadãos como consumidores de seus serviços.

Surge, a partir daí, de acordo com Habermas, um consenso fabricado, sem muita relação com a opinião pública, já que abre mão da discussão e da concorrência aberta:

"A publicidade imita aquela aura de prestígio pessoal e de autoridade supranatural que antigamente era conferida pela esfera pública representativa".

Entretanto, antes desse fenômeno ocorrer, foi detectada uma nova função política para a publicidade. Tal função foi nomeada por Habermas como ativismo jornalístico de organizações. Essa atividade se formou a partir de associações que transformaram os interesses privados de muitos indivíduos em interesse público, para, através disso, buscar nesse público uma aprovação que pudesse ratificar os acordos da instituição.

Assim, essas instituições não-estatais, como os partidos políticos, começaram a se manifestar através de seus grandes organizadores, que são, na verdade, os gerentes de suas próprias posições que, freqüentemente, se fazem passar por pressões sociais exercidas sobre o Estado e legitimadas pelo público que a instituição representa.

Essa mudança de função atinge também o Estado, que vai continuamente se burocratizando, sendo tomado por um grande número de especialistas que atuam ao lado de alguns poucos tomadores de decisões. Entra em cena, então, o "autêntico funcionário do partido", sem qualquer autonomia e completamente 
vinculado às determinações de seus líderes.

A partir daí, começa, então, a se definir a relação do usuário com o Estado, que não se caracteriza pela participação política, mas "por um posicionamento genérico de demanda que espera atendimento sem querer propriamente impor decisões". É uma relação que se estabelece dentro dos planos administrativos do Estado burocrata e prestador de serviço, que, por fim, abre mão da discussão ideológica e se torna um produto para ser consumido.

Enquanto Habermas percebe este Estado prestador de serviço, Baudrillard detecta o desinteresse da sociedade pela classe política.. O autor vê um público desconectado das decisões políticas. Baudrillard concede parte desse descrédito, em primeiro lugar, ao fim da representação política.

Ao fato da classe política render-se à razão sentimental e procurar reger-se conforme os princípios que apregoa. Naturalmente trata-se de uma construção irônica do autor, que não vê na classe política bons exemplos de sobriedade de princípios.

A segunda causa, essa, sem dúvida, mais contundente, está ligada à construção de uma "microssociedade paralela" formada pela classe política. Tal microssociedade, na intenção de se perpetuar, produz uma "confusão endógama de todas as tendências - essa aliança incestuosa entre a direita e a esquerda (...)", afastando-se da sociedade real, que, por sua vez, não abre mão de desfrutar o espetáculo que a política lhe proporciona.

De acordo com Baudrillard, é justamente através do espetáculo, principalmente o da caça à corrupção, que a classe política se "purifica", sacrifica-se em "doses homeopáticas" e garante, com isso, a própria reprodução.

Entendo, ao contrário de ambos os pensadores, que a relação da sociedade com o político não se distancia, mas altera seu enfoque para uma relação de consumo que prima pela eficiência.
É, como diz Habermas, uma estrutura onde o cidadão se articula através do seu poder de compra na esfera privada e se torna, por sua vez, consumidor de plataformas políticas. Não se constitui, portanto, em um afastamento do Estado, mas de uma convivência que se dá em uma esfera diferenciada daquela a que estávamos habituados até pouco tempo, quando tudo era de ordem políticoideológica.

O ideal político, assim, passa a ser pano de fundo apenas para a ação políticoadministrativa concreta. Naturalmente, tal ação não pode ser privada de seu conteúdo ideológico ou se tornaria vazia de sentido. De qualquer forma, as questões ideológicas perdem relevância ante a necessidade de eficiência da qual o Estado prestador de serviço tem priorizado.

É basicamente a mesma lógica de consumo da qual Baudrillard trata em $A$ sociedade de consumo, que é definida como a busca pela felicidade, "o equivalente autêntico da salvação". A política brasileira oferece, inclusive, inúmeros exemplos de "salvadores", que se apresentam durante as campanhas eleitorais, recebendo o tratamento publicitário de um autêntico produto à venda.

Com um Estado burocrata e a escassez de discussões ideológicas abrangentes, a política acaba se tornando um espetáculo político, já que, de acordo com Baudrillard, sua classe desintegrase aos olhos da sociedade, que apenas admira o star system político-midiático que, no entanto, mantém sua estrutura íntegra.

É a classe política produzindo o discurso da "razão sentimental", que antr opofagicamente procura culpados em seu próprio meio para manter a reprodução do show capaz de garantir sua própria sobrevivência. É também o que detecta Maffesoli, quando afirma que a política perde sua razão de ser, já que não é mais capaz de buscar um futuro terreno melhor, por ser ritualística, sem qualquer adiamento do gozo. Assim, torna-se um espetáculo.

É o "concurso" da caça às bruxas, 
onde quem ganha é aquele que apresentar o melhor capital político, que detiver o poder simbólico do discurso verdadeiro, tal qual o entende Pierre Bourdieu, ou seja, a crença depositada sobre o políticoindivíduo. "É um poder que existe porque aquele que lhe está sujeito crê que ele existe", manifestando-se assim como a "potência mágica" da credibilidade.

A verdade do discurso político está, assim, intimamente ligada à capacidade do enunciante em "fazer crer na sua veracidade". Essa idéia de credibilidade do discurso também está muito presente na obra de Foucault que fala em uma "polícia discursiva", onde o credível ou o verossímil devem respeitar uma série de pré-requisitos para serem compreendidos como tal.

O capital político é assim a força motriz de produção do espetáculo político, que consiste na desintegração de indivíduos-políticos para garantir a sobrevivência de toda a classe.

Esse discurso tornou-se necessário já que o Estado não é capaz de produzir glamour, visto que sua relação com a sociedade limita-se às questões burocráticas típicas de um prestador de serviço .

\section{Referências}

BAUDRILLARD, Jean. Tela total: mito-ironias da era do virtual e da imagem. Porto Alegre, Sulina. 1997.

. A sociedade de consumo. Lisboa, Edições 70. 1995.

BOURDIEU, Pierre. 0 poder simbólico. Rio de Janeiro, Bertrand. 1989.

FOUCAULT, Michel. A ordem do discurso. São Paulo, Loyola. 1996.

HABERMAS, Jürgen. Mudança estrutural da esfera pública. Rio de Janeiro, Tempo Brasileiro. 1984.

MAFFESOLI, Michel. A transfiguração do político: a tribalização do mundo. Porto Alegre, Sulina. 1997. 